DOI: http://dx.doi.org/10.20435/1324

\title{
Cervejaria artesanal: modelo de fábrica diferenciado com ênfase no baixo impacto ambiental a ser implantado no município de Campo Grande, MS
}

\begin{abstract}
Artisan brewery: differential factory model with emphasis on low environmental impact to be implemented in Campo Grande county, MS
\end{abstract}

Maria Augusta de Castilho ${ }^{1}$

Alex Maymone ${ }^{2}$

Lina Yule Queiroz de Oliveira ${ }^{3}$

${ }^{1}$ Pós-Doutorado em Linguística. Doutorado em Ciências Sociais História do Brasil. Professora no Curso de História e Coordenadora do Programa de Pós-Graduação em Desenvolvimento Local da UCDB. E-mail: m.a.castilho@terra.com.br

${ }^{2}$ Especialista em Ensino da Arquitetura pela Universidade para o Desenvolvimento do Estado e da Região do Pantanal (UNIDERP). Professor no Curso de arquitetura da UNIDERP e orientou parte desta pesquisa E-mail: aluex@terra.com.br

${ }^{3}$ Mestranda no Programa de Pós-graduação em Desenvolvimento Local da Universidade Católica Dom Bosco (UCDB). E-mail: lina_afowl@hotmail.com 


\section{RESUMO ABSTRACT}

A Revolução da Cerveja Artesanal ocorreu em 1980, quando alguns fabricantes buscaram resgatar a qualidade perdida na produção de cerveja pelas grandes indústrias, que fabricavam uma bebida fraca e com poucos sabores para atender um maior número de consumidores. Fartos dos produtos massificados, procuraram recuperar os valores da bebida milenar, suas tradições, aromas e sabores. O movimento se propagou pelo mundo e atualmente o Brasil conta com cerca de 200 pequenas cervejarias artesanais, que usam apenas ingredientes naturais em suas receitas, sem qualquer tipo de aditivo químico. $\mathrm{O}$ estudo foi pautado no método dedutivo, com pesquisas bibliográficas e observações. 0 objetivo foi o de compreender a importância da cerveja artesanal no âmbito mundial e local, a proposta de implantação de uma cervejaria no município de Campo Grande, MS, para fornecer, além do produto final, o enriquecimento cultural e educacional para os consumidores, com foco na sustentabilidade e no desenvolvimento local.
The Craft Beer Revolution occurred in 1980, when some manufacturers sought to recover the lost quality in beer production by major industries, who made a weak drink and a few flavors to meet a greater number of consumers. Fed up with mass products sought to retrieve the values of the ancient drink, traditions, aromas and flavors. The movement has spread around the world, and Brazil currently has about 200 small craft breweries that use only natural ingredients in your recipes without any chemical additives. The study was guided by the deductive method, with bibliographic research and observations. The goal was to understand the importance of craft beer in the global and local level, the proposed deployment of a brewery in the city of Campo Grande, MS, to provide, in addition to the final product, the cultural and educational enrichment for consumers, focusing sustainability and local development.

\section{KEY WORDS}

craft beer

brewery

local development

sustainability

territory 


\section{INTRODUÇÃO}

A produção e consumo de cerveja são algumas das atividades mais antigas praticadas pelo homem, descoberta há mais de 6.000 anos na Mesopotâmia e, atualmente, é a bebida alcoólica mais consumida do mundo. Nas últimas décadas, tem sido observado o crescimento mundial do mercado de cervejas artesanais, que teve início em 1980, nos Estados Unidos da América do Norte, com o movimento denominado - The Craft Beer Revolution (A Revolução da Cerveja Artesanal), no qual os fabricantes buscam recuperar os valores originais da cerveja com tradição e inovação, resgatando seus sabores e aromas.

O movimento já se expandiu ao redor do globo, não sendo diferente no Brasil, que é visto como grande mercado com potencial devido a sua diversidade e riqueza natural e cultural. Atualmente há mais de 200 cervejarias artesanais por todo o território do país. Em sua produção, não são usados aditivos químicos, apenas produtos naturais que, quando bebidos com moderação, trazem benefícios à saúde, com antioxidantes naturais, nutrientes e vitaminas.

0 setor cervejeiro nacional corresponde a $2 \%$ do PIB brasileiro e é grande gerador de empregos diretos e indiretos. Traz benefícios para diversos setores como o turístico, gastronômico, educacional, cultural, entre outros. É o setor que mais arrecada impostos, porém, no caso das microcervejarias eles são cobrados igual ao das macrocervejarias, não sendo observado o número de litros produzidos, o que faz o custo final das garrafas de cervejas artesanais serem cerca de $60 \%$ apenas de impostos.

A cidade de Campo Grande, no estado de Mato Grosso do Sul, é marcada por sua diversidade de costumes e tradições devido à herança deixada pela imigração, possuindo potencial para produção de um vasto leque de cervejas de diferentes estilos e com variedade de produtos utilizados em suas receitas. As cervejarias 
artesanais refletem a cultura da região e exploram sabores e estilos ignorados pelas grandes indústrias.

0 presente estudo apresenta uma proposta de implantação de uma cervejaria artesanal que forneça ao público mais que apenas a cerveja e sua degustação, mas também um enriquecimento educacional e cultural. A pesquisa será desenvolvida em harmonia com os recursos e as características naturais da região onde vai ser implantada, visando à redução de seu impacto no meio ambiente.

\section{ASPECTOS HISTÓRICOS DA CERVEJA}

A cerveja, segundo a Carta de Florianópolis ${ }^{1}$, é a terceira bebida mais consumida no mundo, atrás apenas da água e do chá. Ela tem importância histórica e cultural para a humanidade, acompanhando-a há milhares de anos. Hoje em dia, já se tornou a bebida alcoólica mais consumida no mundo (NELSON, 2005).

Acredita-se que seu surgimento foi acidental e ocorreu na antiga civilização suméria, localizada na Mesopotâmia, onde hoje está o Iraque, aproximadamente há 6.000 anos A.C., quando o homem conheceu o processo de fermentação, provavelmente esquecendo seu pote de cereais na chuva ou devido ao contato de água com pão deixado ao ar livre (MORADO, 2009). A Mesopotâmia, considerada o berço da civilização, tinha como principais povos os sumérios e os babilônicos. Os babilônicos são responsáveis pelo Código de Hamurabi (1.700 a.C.), possivelmente o primeiro código de leis da humanidade que regulamentava a sociedade, estabelecendo regras de convivência, e nele já havia critérios de produção de cerveja, leis de consumo e comercialização.

Ainda segundo Morado (2009), no Egito Antigo, todos os cidadãos tinham direito a uma ração de cerveja diária conforme

\footnotetext{
${ }^{1}$ Documento produzido por cervejeiros reunidos no 6을 Encontro Nacional de Cervejas Artesanais em junho de 2011 na cidade de Florianópolis, buscando a manifestação sobre a tributação alta do setor.
} 
seu status social, a cerveja era vista como um 'pão líquido' e de valor nutricional. Possuía valores sociais notáveis, como oferenda aos mortos, presentes aos faraós e também era de extrema importância para a economia na época, usada como moeda de troca e como parte dos salários dos trabalhadores.

Os romanos aderiram à cerveja difundindo-a pelos novos territórios conquistados. Na Idade Média, um dos maiores motivos de mortalidade era devido à água contaminada levando a cerveja a ser a bebida preferível para o consumo já que, em seu processo, a água era fervida e as impurezas filtradas. Em 1516, o Duque Guilherme IV da Baviera criou a Reinheitsgebot, a Lei da Pureza da Cerveja, afirmando que a cerveja deveria ser fabricada apenas com água, cevada e lúpulo (DRUMOND; OLIVEIRA, 2013). Com a invenção da máquina a vapor e a pasteurização, a cerveja foi ainda mais difundida na sociedade, e sua fabricação se expandiu.

Os índios que habitavam no Brasil já produziam uma bebida fermentada de mandioca e do milho, chamada Cauim, que era tomada pura ou misturada com frutas (INFOPÉDIA, 2015). Com a vinda da família real portuguesa para o Brasil e a abertura dos portos, a cerveja foi trazida pelos imigrantes europeus que se instalaram nas novas cidades (DRUMOND; OLIVEIRA, 2013). No final do século XIX, ela começou a ser produzida, expandindo seu consumo pelo Brasil com a grande quantidade de fábricas que surgiram na época.

Hoje em dia, por conta da grande expansão e da busca por lucro, muitas cervejarias produzem um produto de massa, barato, de baixa qualidade e fácil de ser encontrado, o que levou as pessoas, nos últimos anos, a procurar voltar às origens da cerveja, seus produtos artesanais e ingredientes naturais. 


\subsection{Conceito de cerveja artesanal}

Artesanais são cervejas que possuem cuidados maiores em sua produção, que é vendida em menor escala e mais limitada. Há um leque de receitas, mas todas são produtos naturais, livres de conservantes e aditivos, buscando inovar e surpreender o consumidor com seu sabor e aroma. São vários os tipos de cervejas:

- Homebrew (Cerveja Caseira): é a cerveja produzida em casa, sem fins comerciais, como hobby. A prática é difundida no mundo todo, principalmente Estados Unidos da América do Norte e Europa. Muitos cervejeiros caseiros que se interessam, evoluem e abrem microcervejarias.

- Cerveja Massificada: são produzidas nas grandes indústrias de cerveja do mundo, como a Ambev, por exemplo, com foco principal nas vendas, o que resulta em produtos fracos, de poucos aromas e sabores, já que o objetivo é atingir o maior número de consumidores.

Segundo Daniel Wolff, a cerveja artesanal pode ser pequena, quando a produção anual é de até milhões de barris; independente, quando $25 \%$ é de propriedade autônoma ou controlada por outra empresa; tradicional, quando usam cevada, trigo, aveia, ervas e especiarias (MESTRE-CERVEJEIRO.COM, 2014).

\subsection{A revolução da cerveja artesanal}

Hindy (2015) assinala que o movimento chamado The Craft Beer Revolution (A Revolução da Cerveja Artesanal) deu-se nos Estados Unidos da América do Norte, na década de 1980, com o surgimento de microcervejarias que buscavam resgatar a qualidade perdida na produção de cerveja. Tiveram por início o homebrewing, o que, na época, levou alguns praticantes a se tornarem empreendedores e fundarem suas próprias microcervejarias, buscando resgatar o aroma, sabor e qualidade da cerveja, não 
lucros e grandes quantidades (HINDY, 2015). A cerveja artesanal é preferida pela qualidade, e não pela quantidade.

Nos Estados Unidos da América do Norte, há 30 anos, o movimento começou aproximadamente com 90 cervejarias artesanais. Em 2014, foram registrados cerca de 3.464, entre eles 3.418 artesanais e 46 cervejarias massificadas, segundo a Brewers Association (2015), vem crescendo 19\% desde 2013 e empregando aproximadamente 115.469 pessoas. As cervejas artesanais já superaram em números de venda a Budweiser, a principal cerveja americana, de marca global vendida em dezenas de países (MICKLE, 2014).

Samuel Cavalcanti, um dos sócios da Cervejaria Bodebrown, afirma que: "as grandes cervejarias são como bancos que esperam apenas o retorno financeiro. Para as microcervejarias, o que está em jogo é o trabalho do artista. São cervejas com propósitos diferentes" (SEBRAE, 2014, p. 5).

\section{A CERVEJA ARTESANAL NO BRASIL}

Depois da revolução das cervejarias americanas, a onda de cervejas artesanais se espalhou pelo mundo, inclusive no Brasil no começo de 1990, porém ainda tímida, com as cervejas importadas surgindo aos consumidores e algumas primeiras fábricas de cerveja artesanal se estabelecendo no país. Exemplos que atuam até hoje no mercado são a Baden Baden de Campos do Jordão, a Dado Bier de Porto Alegre, A Wäls de Belo Horizonte e a Cervejaria Colorado de Ribeirão Preto.

Hoje em dia se estima que existam cerca de 200 microcervejarias no Brasil, espalhadas por todo o seu território, concentradas nas regiões Sul e Sudeste (SCHMIDT, 2013). Blumenau, Belo Horizonte, Curitiba e Porto Alegre, por exemplo, se tornaram grandes polos de fabricação de cerveja artesanal (REVISTA VIP, 2011). Estudos feitos pela Mintel Group em 2014, mostram que, 
em apenas três anos, a produção de cervejas artesanais cresceu $36 \%$ no país, enquanto as cervejas convencionais tiveram queda de $3 \%$ no período.

Jonny Forsyth, analista de bebidas da Mintel Group, acredita que o mercado de cerveja artesanal do Brasil é considerado o mais inovador do mundo devido à abundância de matérias-primas encontradas na localidade, à diversidade da natureza brasileira, o que possibilita a criação de rótulos feitos com criatividade (FERNANDES, 2014). A Cervejaria Colorado de Ribeirão Preto SP é grande modelo de cervejaria com ingredientes locais, tendo receitas com rapadura, mandioca, mel de laranjeira e café, todas buscando incrementar o jeito brasileiro com tradição e inovação. A cervejaria é detentora de diversos prêmios pelos produtos e hoje exporta para a França e Estados Unidos.

As cervejas artesanais possuem um crescimento que dobra a cada ano, portanto seu potencial de expansão é enorme. Segundo a Associação Brasileira da Indústria da Cerveja (CERVBRASIL, 2014), o Brasil é o terceiro maior produtor de cerveja do mundo, produzindo cerca de 13 bilhões de litros por ano, ficando atrás apenas da China e dos Estados Unidos. Nos últimos cinco anos, veio o aumento do consumo interno de alimentos, e a cerveja foi o que teve maior crescimento de consumo (MAPA, 2013). Os consumidores estão exigindo produtos de melhor qualidade, pelos quais se dispõem a pagar um pouco mais caro.

\subsection{A cerveja na economia brasileira}

O Sindicato Nacional da Indústria da Cerveja (SINDICERV) aponta que o mercado das microcervejarias já movimenta quase $\mathrm{R} \$ 2$ bilhões e encerrou o ano de 2014 com 11\% de participação no mercado brasileiro. 0 crescimento do mercado impulsiona uma série de negócios, ramificando-se desde a compra de matéria-prima até as lojas de distribuição (SEBRAE NACIONAL, 2015). 
O setor cervejeiro, de acordo com a CervBrasil (2014), é responsável por $2 \%$ do PIB brasileiro e é um dos setores que tem um dos maiores efeitos na economia, sendo parceiro de peso do desenvolvimento nacional. 0 setor de bebidas frias, que engloba cerveja, refrigerante, sucos, chás e isotônicos, é o que mais gera empregos no país. Para cada emprego gerado em uma fábrica de cerveja, outros 52 são criados na cadeia produtiva. Apenas no Nordeste, as cervejarias representam $20 \%$ de toda a indústria de transformação da região.

O setor das cervejas artesanais também amplia o setor de equipamentos, distribuição, revenda, a criação de cursos profissionalizantes e workshops para os interessados em se aprofundar nesse universo e até mesmo a indústria de copos e taças, já que cada estilo pede um copo diferente. É um setor que beneficia uma grande cadeia econômica.

\subsection{Os impostos no Brasil}

Nas microcervejarias,p os ingredientes são em sua maioria importados: o malte vem dos Estados Unidos e da Europa, o lúpulo não é plantado no Brasil e hoje já se encontra uma empresa brasileira que fornece as leveduras, mas, muitas vezes, ainda importadas da França ou dos Estados Unidos (MESTRE-CERVEJEIRO. COM, 2014).

Os impostos cobrados chegam até $60 \%$ do preço da garrafa vendida a consumidor. As cervejas artesanais brasileiras custam em média três vezes mais que as industriais (BARBOZA, 2013). Por serem fábricas de bebida alcoólica, as microcervejarias são tratadas como macrocervejarias pelo Ministério da Agricultura, Pecuária e Abastecimento e possuem os mesmos tributos a pagar, mesmo tendo uma produção imensamente menor. 


\section{BENEFÍCIOS DA CERVEJA ARTESANAL PARA A SOCIEDADE}

Com a 'gastronomização', o consumidor está mais exigente, buscando rótulos com qualidade, estudando suas composições e aprendendo estilos de cerveja que, até então, não eram conhecidos por ele (CLUBEER, 2012). A preferência atual por produtos gourmet não é novidade e pode ser vista pelos surgimentos recentes de grande número de lojas servindo esses produtos, seja brigadeiro gourmet ou hambúrguer artesanal, exemplos das novas ofertas que já estão concorrendo em números de venda com as comidas industrializadas.

As grandes cervejarias costumam acrescentar milho ou arroz no processo de fabricação como forma de baratear o produto. Segundo estudo da USP de Piracicaba em 2012, as grandes marcas de cerveja populares brasileiras estão no limite da porcentagem permitida de milho como matéria-prima para cerveja. Já as cervejarias artesanais usam puro malte, sem oxidantes, conservantes, estabilizantes, corantes ou aditivos. Quando bebidas com moderação, trazem benefícios à saúde, com antioxidantes naturais, nutrientes, vitaminas e minerais.

Comprá-la é fácil, hoje já está nos supermercados, lojas especializadas e até em clubes de assinatura que entregam a cerveja em casa, negócio que está em expansão nos últimos anos. 0 cliente escolhe o plano pelo preço e número de garrafas e mensalmente recebe o kit em sua casa. 0 maior clube atuante do país é o Have a Nice Beer, que trabalha apenas com rótulos inéditos no mercado e conta com mais de dez mil associados (KROEHN, 2013). 0 assinante recebe também bolachas personalizadas e uma revista informativa sobre a cerveja adquirida, características, receitas de harmonização e notícias do mundo cervejeiro (HAVE A NICE BEER, s.d.).

As fábricas de cerveja são importantes para conhecer o processo de criação dos rótulos tradicionais e dos inovadores. 
Inúmeras cervejarias abrem suas portas para receber curiosos, apaixonados e entendedores do ramo, o que incentiva o chamado turismo etílico. A estratégia alemã de criar um bar da fábrica para divulgar o conceito da marca e seus rótulos já provou fazer sucesso no Brasil e ganhou vários adeptos. Ela também permite servir a bebida na temperatura ideal, no copo certo e ainda harmonizada com um prato (BARBOZA, 2013).

A harmonização entre alimentos e cerveja está em alta e é uma busca pelo prazer sensorial em que as características de ambas são reveladas (MESTRE-CERVEJEIRO.COM, 2014).

0 turismo etílico também engloba os festivais cervejeiros que crescem todos os dias no país, unindo as pessoas pela cerveja e também oferecendo boa música e boa comida. São vários ao longo do ano, porém o maior festival de cervejas artesanais do país é o Festival Brasileiro de Cerveja, que ocorre todo ano em Blumenau, Santa Catarina. O festival celebra o mercado de cervejas artesanais com degustações, palestras, workshops, shows e gastronomia personalizada para harmonizar com os diversos estilos de cerveja, oferecidos em quatro dias de programação com mais de 600 rótulos disponíveis.

Os objetivos são proporcionar ao público a oportunidade de conhecer, degustar e avaliar a imensa variedade de produtos, estimulando também aos vendedores, produtores, donos de bares e de restaurantes a chance de ampliar o seu mercado de atuação. Assim, uma das metas é ampliar o calendário de eventos da cidade trazendo benefícios econômicos diretos e indiretos e também fortalecer a identidade da cidade e sua região (FEIRAS \& NEGÓCIOS, 2013). Blumenau é considerada a 'Capital Nacional da Cerveja' devido à criação da Oktoberfest (tradicional festa alemã, celebrada em Munique desde 1810), do Roteiro das Cervejarias Artesanais e do Museu da Cerveja.

0 preço no mercado de cerveja artesanal não exerce vantagem sobre a qualidade do produto (SEBRAE, 2014). Segundo 
a Carta de Florianópolis (2011), seus produtos são mais caros devido aos impostos e ingredientes importados, porém as microcervejarias não estimulam a ingestão de quantidade, e sim de qualidade, o que ocorre também na indústria do vinho (BREJAS, 2016). A cerveja artesanal mostra que vale a pena pagar mais caro por uma garrafa cuja produção é cuidadosa, com ingredientes bem selecionados e rótulos bem pensados, tanto que usa como lema 'beba menos, beba melhor'.

\section{A CERVEJA ARTESANAL EM CAMPO GRANDE, MS}

A cidade de Campo Grande é a capital do estado de Mato Grosso do Sul, localizada na região Centro-Oeste do Brasil. A área de seu município é de $8.092,95 \mathrm{~m}^{2}$, segundo os dados disponibilizados pela Prefeitura Municipal no Perfil Socioeconômico de 2014. Possui uma área urbana de $35.903,53$ hectares e conta com 786.797 habitantes (IBGE, 2010). Localiza-se em uma região típica do cerrado e, devido à cor de seu solo, recebeu o apelido de Cidade Morena. Possui clima tropical semiúmido, caracterizado pelo verão quente e úmido e o inverno ameno e seco, com temperaturas variáveis. A região é bem provida de chuvas concentradas de novembro a março.

Foi fundada por mineiros em 1872, com a chegada de José Antônio Pereira, e emancipada em 1899, completando 116 anos em 2015. A construção da estrada de Ferro Noroeste do Brasil, em 1914, contribuiu para o desenvolvimento urbano local e regional, trazendo novas culturas, oportunidades de negócios e tornando-se uma cidade eclética, com imigrantes árabes, alemães, japoneses, portugueses, paraguaios e migrantes gaúchos, mineiros, paulistas, entre outros. Seus costumes foram incorporados na cultura campo-grandense e sobrevivem até hoje. Os imigrantes e migrantes exerceram enorme influência na economia e cultura local (PMCG, 2014). A imigração japonesa na cidade, por exemplo, completou 
seu centenário em 2014, junto com os 115 anos da capital.

O estado de Mato Grosso do Sul abriga a maior parte do Pantanal, que é considerada a maior planície alagável do mundo e conta com uma diversidade de fauna e flora encontradas apenas na região, o que inevitavelmente atrai um grande número de turistas. Também é um estado de terras férteis e com alguns dos maiores rebanhos de gado bovino do país, o que causou a expansão da agropecuária e do ecoturismo (BRASIL, s.d.).

A Secretaria Municipal de Desenvolvimento Econômico, Ciência e Tecnologia e do Agronegócio (SEDESC) promove o desenvolvimento econômico e social da cidade de Campo Grande, MS. No setor da indústria, as ações são direcionadas ao fomento empresarial por meio de incentivos fiscais, com a implantação de polos empresariais visando alavancar os setores que possam empregar mão de obra local e também auxiliar no incremento de recursos para o referido município (PMCG, 2014). A cidade possui quatro polos empresariais que contam com 106 empresas e mais de nove mil trabalhadores.

Trazido pelos migrantes gaúchos e enraizados devido à alta atividade pecuária, o churrasco tornou-se a refeição mais popular e tradicional da cidade. Boa parte das celebrações envolve o prato e, em muitas famílias, ele virou refeição presente em todos os finais de semana, tornando-se uma tradição e também uma atividade social.

O tereré, patrimônio imaterial e cultural do estado, é de origem paraguaia e é consumido a todo momento, exercendo grande função social. As altas temperaturas da cidade na maior parte do ano elevam o consumo de bebidas como o tereré e a cerveja, transformando o hábito de consumo, sendo ponto favorável para o mercado de cervejas artesanais (SEBRAE, 2014).

Em Campo Grande, há lojas especializadas em cervejas artesanais e importadas, como a Mr. Beer, rede de cervejas especiais presente no Shopping Campo Grande, o principal da cidade. 
Também há a loja Chicken Beers e a recém-inaugurada - Mestre Cervejeiro, que se destaca por oferecer, além de cervejas, cursos e, ainda, por organizar viagens para destinos cervejeiros do Brasil e do exterior. Alguns bares estão ampliando sua carta de cerveja, como: a Mercearia Bar, que conta com mais de 150 rótulos. No entanto a loja que se sobressai é a Casa do Chef, que trabalha com mais de 200 rótulos artesanais nacionais e importados e oferece espaço para degustação, contando com um clube de assinatura mensal. Na produção, a Cantina Mato Grosso está no mercado de chopes artesanais há 31 anos e fabrica quatro estilos diferentes, nenhum deles possuindo ingredientes químicos.

Enfatiza-se, em outro aporte, que o potencial de consumo de cervejas no Brasil mostra que, nas cidades do Norte, Nordeste e Centro-Oeste, há escassez de marcas comercializadas de cervejas artesanais, as quais devem ser olhadas como um mercado em potencial (SEBRAE, 2014). As cervejarias artesanais podem refletir a cultura da região e explorar sabores e estilos ignorados pelas grandes indústrias.

Assim, em algumas regiões em que a população pode preferir determinado estilo de cerveja, uma microcervejaria pode atender essa demanda, algo que uma grande indústria nunca faria com um público tão limitado. Como é marcada pela enorme diversidade de costumes devido à herança deixada pela migração/imigração, a cidade passa a ter um potencial para produção de um vasto leque de cervejas, atendendo diferentes gostos e podendo lançar rótulos homenageando as diferentes culturas da região, usando ingredientes presentes em cada cultura. Até mesmo para ocasiões especiais, é possível criar cervejas sazonais (produzidas apenas em determinada época do ano) para eventos como, por exemplo, o Bon Odori, festa tradicional japonesa realizada anualmente em Campo Grande.

A cidade já conta com a fábrica de cervejas artesanais: a Morena Bier, que produz três tipos de cervejas, uma delas contan- 
do com mandioca na receita; a cerveja MoageM, a artesanal mais famosa de Campo Grande, cuja fábrica em construção está quase completa, com previsão de inauguração para julho de 2015. São sete estilos de cerveja, algumas de sabores regionais, com tereré e outra com guavira (VITORINO, 2013).

A cultura da cerveja artesanal em Campo Grande, ainda que pequena, tem potencial para ampliação, uma vez que consumidores e cervejeiros são interessados, curiosos e apaixonados pelo assunto. Mais que isto, outro fator positivo para a implantação de uma nova fábrica, como a que está sendo proposta, é o seu potencial de atração turística e, consequentemente, econômica para o Estado, também com a geração de novos empregos diretos e indiretos, contribuindo para o desenvolvimento de toda a região.

\subsection{Proposta de intervenção}

Com o movimento de cervejas artesanais ganhando mais força no país, o objetivo da proposta é fornecer, em Campo Grande, um espaço diferenciado para apreciação e conhecimento do produto, criando um local que transcenda a fabricação e o consumo, e ainda agregando outros valores, culturais, artísticos e educacionais. A ideia é proporcionar, além da degustação de sabores diferenciados, um enriquecimento cultural nos consumidores.

0 projeto contará com a fábrica, um bar para apreciação da cerveja, onde o consumidor terá a chance de ver seu processo de fabricação enquanto saboreia a bebida. 0 projeto contará ainda com roteiros para visitas às instalações, salas para cursos e workshops, laboratórios para aulas de análise química e produção, loja de souvenirs e insumos onde poderão ser compradas matérias-primas e produtos para homebrew, biergarten (jardim da cerveja), de tradição alemã, que é uma grande área reservada à convivência e degustação, e um espaço para exposições e expressões culturais. 
Também apoiará as cervejas ciganas, que são cervejarias que não possuem fábrica e, assim, elas alugam um espaço de uma cervejaria para produzir suas receitas, e cujo nome é pela possibilidade de migração que elas possuem, muitas fazem parcerias com várias cervejarias, produzindo bebidas únicas. É por exemplo, o caso da cervejaria brasileira 2cabeças e da famosa cervejaria dinamarquesa Mikkeller, que produz suas cervejas em diversos países. 0 modelo permite apoio aos cervejeiros sem capital inicial para começar uma fábrica e também uma colaboração com outras cervejarias, tornando-se uma jogada de marketing e atraindo o público delas. Para isso, a fábrica contará com um tanque de fermentação e maturação a mais, destinado às produções ciganas.

Quatro ingredientes compõem a essência da cerveja, a água, o lúpulo, o malte de cevada e a levedura. A água é o corpo da cerveja, ingrediente que constitui cerca de $90 \%$ da sua composição. 0 malte de cevada é responsável pela cor e sabor, o lúpulo dá aroma, amargor, estabilidade e também faz sua conservação natural. Já a levedura é um microrganismo que transforma o açúcar dos grãos de malte em dióxido de carbono, álcool e compostos aromáticos (ILHA et al., 2008). Dependendo do estilo, podem conter ingredientes especiais e diversos, como frutas, vegetais e especiarias (BARBOSA, 2014).

0 processo de criação da cerveja consiste em quatro etapas principais, a produção do mosto, a fermentação, maturação e o acabamento (AQURONE et al., 2001). Na produção do mosto, o malte é moído para facilitar sua conversão em açúcar e misturado com água, em seguida é filtrado e separado do bagaço de malte. Depois, o mosto é fervido para ser estabilizado, e o lúpulo é adicionado, conferindo amargor e aroma, passando por um processo de separação das proteínas e é rapidamente resfriado para receber a levedura na fase da fermentação, quando seus açúcares são transformados em álcool e gás carbônico (AQURONE et al., 2001). Em seguida tem início a maturação, método usado para aprimo- 
rar e refinar os sabores da cerveja, e é nessa etapa que ocorre a carbonatação natural da bebida. No seu acabamento, ela pode ser filtrada, ou não, e preparada para envase em que é engarrafada, passando pela pasteurização, que consiste em aquecer a bebida para sua estabilização microbiológica, estando pronta para o consumo depois (MORADO, 2009).

Pequenos furgões refrigerados farão a distribuição da bebida para os estabelecimentos comerciais, não necessitando de grandes veículos por ser uma microcervejaria, colaborando assim, com a melhor fluidez do trânsito. 0 desnível presente no local de implantação será integrado ao projeto para aproveitar os efeitos da gravidade no processo de produção, auxiliando na economia de água e energia.

A sustentabilidade estará presente em várias etapas do processo. A maior questão é a água, ingrediente que compõe cerca de 90\% da cerveja e usado em grande quantidade, em sua produção como na higienização da fábrica. Para tanto, propõe-se um sistema de captação de águas pluviais, utilizando-as para limpeza, irrigação dos jardins e para sanitários. Placas fotovoltaicas e lâmpadas de LED ajudarão na iluminação e no consumo de energia, assim como o uso da iluminação natural. Em relação ao conforto térmico será implantado o telhado verde, a ventilação natural, cruzada e efeito chaminé, diminuindo a climatização artificial, o que reflete na economia de energia. 0 bagaço do malte usado na produção de cerveja possui índice proteico favorável à ração animal e já é muito usado hoje. Ao invés de ser descartado, ele será vendido para fazendas para servir como complemento na alimentação de rebanhos.

Os materiais utilizados na construção serão regionais para evitar longos transportes e gastos em $\mathrm{CO} 2$, de baixo impacto ambiental, recicláveis, reutilizáveis e renováveis. 0 projeto será feito para estar em harmonia com as características e recursos naturais da região onde vai ser implantado para reduzir seu impacto no meio ambiente. 


\subsection{0 terreno}

O terreno escolhido localiza-se no município de Campo Grande, Mato Grosso do Sul, no bairro Carandá Bosque, Região Urbana do Prosa, nome dado devido à bacia hidrográfica situada no local. A bacia possui grau de criticidade IV, de acordo com a Carta de Drenagem, apresentando problemas como alagamentos e enchentes em alguns pontos, sistema de microdrenagem insuficiente em vários pontos e bocas-de-lobo assoreadas com distribuição regular. As recomendações para a área são implantação de microdrenagem e de sistema adequado para captação e drenagem de águas superficiais, proteção das margens dos cursos d'água, desassoreamento, entre outros.

A cidade conta com setenta e quatro bairros, divididos em sete regiões urbanas. A região urbana do Prosa é a mais beneficiada de parques urbanos, contando com quatro, como o Parque das Nações Indígenas, o mais famoso da cidade.

O bairro Carandá Bosque abriga o Parque Linear do Sóter, criado para acomodar o córrego Sóter, cuja nascente se dá no Parque Ecológico de mesmo nome, no bairro Mata do Jacinto, limite com o Carandá Bosque, e também para permitir o escoamento e infiltração das águas pluviais e manter viva a vegetação ciliar, possibilitando a manutenção de abrigos e alimento para a fauna e estabilizando as margens do curso d'água (PMCG. Secretaria Municipal de Meio Ambiente e Desenvolvimento Urbano, 2015).

Enquadra-se no perfil de consumidor de cerveja artesanal o perfil da população do bairro, onde a idade média é entre 30 a 40 anos e considera a qualidade da cerveja o maior motivo de compra, não o preço (PONZI, s.d.). 0 Carandá conta com diversas conveniências e com o Pão de Açúcar, ambos com vendas regulares de cervejas importadas e artesanais, mas possui apenas um bar onde só vende cervejas pilsen de grandes marcas, e a Cantina Mato Grosso, que fabrica chope artesanal, tendo potencial para a 
construção de uma cervejaria artesanal com bar anexo à fábrica.

O local do terreno é ideal por possuir uma via de rápido e fácil acesso, a Avenida Nelly Martins, mais conhecida como Via Park. A outra rua que o limita é a Rua Mário de Andrade. Devido às exigências do Plano Diretor, o local foi escolhido por ser de melhor acesso para a população e possuir as infraestruturas básicas necessárias e pela beleza da região e seus parques. O Parque Linear do Sóter acompanha a Via Park, onde ficará a fachada principal do projeto. 0 terreno apresenta a infraestrutura básica como rede de energia elétrica, rede de água, rede de esgoto, pavimentação asfáltica e coleta urbana de lixo.

A zona onde o terreno está situado é a Z7, e permite a construção de indústrias até dez mil metros quadrados quando localizados na Macro Zona 1, que é o caso atual. A fabricação de cervejas se enquadra no uso industrial 5 (I5) e 6 (I6). Para o projeto, será considerado como I5, que permite até cinco mil metros quadrados de área construída, o suficiente por se tratar de um microcervejaria. 0 terreno possui $8.658,09 \mathrm{~m}^{2}$, e os índices urbanísticos aplicados à zona são a taxa de ocupação, que é de 50\%, a área permeável mínima é de 12,5\%, o coeficiente de aproveitamento é igual a 2 , e seu índice de elevação é 4 .

0 terreno possui declividade de 7,46\%, que será usada a favor do projeto, aproveitando os efeitos da gravidade nas diferentes etapas do processo de fabricação, resultando em economia de energia. Os tipos de solo presentes na área são o latossolo vermelho escuro de textura média e argilosa e o latossolo roxo poroso e solo argiloso mal drenoso, presente em regiões próximas a corpos d'água. Possui baixa a média susceptibilidade à erosão e permeabilidade do solo apresentando problemas de alagamentos e dificuldades com fundações profundas. 


\section{CONSIDERAÇÕES FINAIS}

O setor cervejeiro mostrou-se importante para a economia de qualquer país e um grande gerador de empregos diretos e indiretos, ocorrendo também a valorização de mão de obra local. As microcervejarias dão benefícios à indústria hoteleira, de entretenimento, gastronômica, entre outras, e o estímulo ao consumo responsável é incentivado, devido à cerveja artesanal ser consumida em volumes menores. 0 setor explora a tradição da bebida com a modernização das fábricas e os conceitos sociais, sendo as cervejarias ativas em programas e eventos locais.

Por ser uma cervejaria artesanal, sua produção será focada nos mercados regionais e locais, valorizando seu diferencial local, explorando sabores e estilos e oferecendo diversificação em seus produtos aliados à tradição e qualidade.

A cerveja está enraizada na cultura da humanidade e é muito mais que apenas uma bebida, é um elemento integrador com valores culturais. 0 projeto contribuirá com a disseminação da cultura da cerveja artesanal no Brasil, ajudando a consolidar o país como uma nova escola cervejeira, beneficiando o turismo, a economia e principalmente o resgate histórico e cultural de uma bebida milenar. 0 foco principal é ir além da cerveja como produto final e consolidar os princípios do movimento de cervejas artesanais, na sustentabilidade e qualidade, valorizando a cultura e o desenvolvimento local.

\section{REFERÊNCIAS}

AQUARONE, E. et al. Biotecnologia na produção de alimentos. São Paulo: Edgard Blücher, 2001.

BARBOSA, C. A história do pão. Portugal: Escola de Viana do Castelo, 2013/2014.

BARBOZA, Marina. O negócio milionário das cervejas artesanais. 16/08/2013. Disponível em: <http://www.istoe.com.br/reportagens/ 
319458_o+negocio+milionario+das+cervejas+artesanais>. 21/01/2016. Acesso em: 5 abr. 2016.

BRASIL. Ministério do Meio Ambiente. Pantanal. [s.d.]. Disponível em: <http://www.mma.gov.br/biomas/pantanal>. Acesso em: 23 abr. 2015.

BREJAS. Menos impostos para as microcervejarias brasileira. 29/06/2011. Disponível em: <http://www.brejas.com.br/forum/mercado/28368menos-impostos-para-as-microcerveja rias-brasileira>: Acesso em: 15 abr. 2016.

BREWERS ASSOCIATION. Craft Brewer Defined. Disponível em: <http:// www.brewer sassociation.org/statistics/craft-brewer-defined/>. Acesso em: 13 abr. 2015.

CERVBRASIL. Associação Brasileira da Indústria da Cerveja. Anuário 2014. Disponível em: <http://www.sebrae2014.com.br/Sebrae/ Sebrae\%202014/Estudos\%20e\%20Pesquisas/2014_0 7_08_RT_ Agroneg\%C3\%B3cio_Potencial_de_consumo_de_cervejas_no_Brasil. pdfhttp://cervbrasil.org.br/2014/12/cervbrasil-lanca-primeiroanuario-setor-cervejeiro/>. Acesso em: 6 abr. 2015.

CLUBEER. Entrevista com Bia Amorim - Sommelier. 23/11/2012. Disponível em: <http://www. clubeer.com.br/blog/post/81-entrevista_ com_bia_amorim_-_sommelier>. Acesso em: 23 abr. 2015.

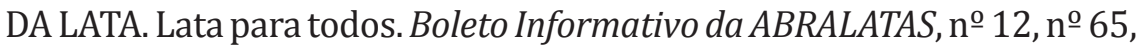
novembro/dezembro, 2015. Disponível em: <http://www.abralatas.org. br/wp-content/uploads/2016/02/jornal_noticias_da_lata_n.65_2015_ final_web.pdf>. Acesso em: 15 abr. 2016.

DRUMOND, Hélcio; OLIVEIRA, Henrique. Brasil Beer - o guia de cervejas brasileiras. [S.l.]: Gutenberg, 2013.

FEIRAS \& NEGÓCIOS. Festival brasileiro da cerveja de 20 à 23 de março em Blumenau. 13/03/2013. Disponível em: <http://www.feirasenegocios. com.br/?p=noticiasDetalhe\&noti cia=813>. Acesso em: 20 abr. 2015.

FERNANDES, Fátima. Quem são os empreendedores por trás do 'boom'das microcervejarias. 29/12/2014. Disponível em: <http://www.dcomercio. com.br/categoria/ne gocios/quem_sao_os_empreendedores_por_tras_ do_boom_das_microcervejarias>. Acesso em: 20 abr. 2105. 
HAVE A NICE BEER. Quem somos. [s.d.]. Disponível em: <https://www. haveanicebeer.com.br/hnbinfo/institucional/quem-somos>. Acesso em: 6 abr. 2015.

HINDY, Steve. A revolução da cerveja artesanal. [S.l.]: Edições Tapioca, 2015.

ILHA, Eunice Cassanego et al. Rendimento e eficiência da fermentação alcoólica na produção de hidromel. Boletim de pesquisa e desenvolvimento, n. 8, Empresa Brasileira de Pesquisa Agropecuária (EMBRAPA), dez. 2008.

INFOPÉDIA. Dicionário da língua portuguesa com acordo ortográfico. Porto: Porto Editora, 2003-2015. Disponível em: <http://www. infopedia.pt/\$historia-do-cauim>. Acesso em: 10 abr. 2015.

INSTITUTO BRASILEIRO DE GEOGRAFIA E ESTATÍSTICA (IBGE). Censo demográfico 2010. Disponível em: <http://www.ibge.gov.br/home/ estatistica/populacao/censo2010>. Acesso em: 10 maio 2016.

KROEHN, Márcio. Clubes de cerveja dobram de tamanho e popularizam bebida artesanal. 02/03/2013. Disponível em: <http://veja.abril. com.br/noticia/economia/clubes-de-cerveja-dobram-de-tamanho-epopularizam-bebida-artesanal>. Acesso em: 4 abr. 2015.

MESTRE-CERVEJEIRO.COM. Por que as cervejas artesanais são mais caras: produção. 02/10/2014. Disponível em: <http://www.mestre-cervejeiro. com/por-que-cervejas-artesanais-sao-mais-caras-producao $>$. Acesso em: 12 maio 2016.

MICKLE, Tripp. Bud Crowded Out by Craft Beer Craze: Faded Beer Brand Unhitches Clydesdales in Favor of Fresher Pitches to Young People. The Wall Street Journal, Nova York, 23 nov. 2014. Business. Disponível em: <http://www.wsj.com/articles/budweiser-ditches-theclydesdales-for-jay-z-1416784086>. Acesso em: 01 abr. 2015.

MINISTÉRIO DA AGRICULTURA, PECUÁRIA E ABASTECIMENTO (MAPA). Crescimento da renda aumenta demanda por alimentos no Brasil. 14/10/2013. Disponível em: <http://www.agricultura.gov.br/ comunicacao/noticias/2013/10/crescimento-da-renda-aumentademanda-por-alimentos-no-brasil>. Acesso em: 5 jun. 2016. 
MORADO, Ronaldo. Laurosse da cerveja. [S.l.]: Lafonte, 2009.

NELSON, M. The Barbarian's Beverage: A History of Beer in Ancient Europe. [S.l.]: Routledge, 2005.

PREFEITURA MUNICIPAL DE CAMPO GRANDE (PMCG) [município]. Perfil socioeconomico de Campo Grande 2014. Disponível em: <http://capital. ms.gov.br/egov/imti/perfil-pageflip/perfil-2014.html>. Acesso em: 12 abr. 2015.

PREFEITURA MUNICIAPL DE CAMPO GRANDE (PMCG). Secretaria Municipal de Meio Ambiente e Desenvolvimento Urbano. [s.d.] Parques municipais. Disponível em: <http://portal.capital.ms.gov.br/semadur/ canaisTexto?id_can=6461>. Acesso em: 12 abr. 2015.

PONZI, Fabian. Quais são os hábitos e as tendências do consumo de cerveja no Brasil. [s.d.]. Disponível em: <http://www.bebendobem.com. br/2015/02/quais-sao-os-habitos-e-tendencias-consumo-de-cervejasbrasil/>. Acesso em: 23 abr. 2015.

REVISTA VIP. A revolução da cerveja artesanal: microcervejarias nacionais apostam na alta qualidade para conquistar o consumidor comum. 10/03/2011. Disponível em: <http://vip.abril.com.br/arevolucao-da-cerveja-artesanal>. Acesso em: 8 abr. 2015.

SCHMIDT, Marina. Tributação da cerveja prejudica produtores artesanais. 10/07/2013. Disponível em: <http://jcrs.uol.com.br/site/noticia. php?codn=128950>. Acesso em: 22 maio 2016.

SEBRAE. Serviço Brasileiro de Apoio às Micro e Pequenas Empresas. Potencial de consumo de cervejas no Brasil. 08/07/2014. Disponível em: <http://www.sebrae2014. com.br/Sebrae/Sebrae\%202014/ Estudos\%20e\%20Pesquisas/2014_07_08_RT_Agroneg\%C3\%B3cio_ Potencial_de_consumo_de_cervejas_no_Brasil.pdf>. Acesso em: 26 mar. 2015.

SEBRAE NACIONAL. Microcervejarias ganham espaço no mercado nacional. 25/11/2015. Disponível em: <http://www.sebrae.com.br/ sites/PortalSebrae/artigos/microcervejarias-ganham-espaco-nomercado-nacional,fbe9be300704e410VgnVCM1000003b74010aRC RD>. Acesso em: 3 jan. 2016. 
VITORINO, Paula. Tereré e guavira viram sabores de cerveja em MS. Jornal Correio do Estado, Campo Grande, 22 dez. 2013. Notícias. Disponível em: <http://www.correiodoestado.com.br/noticias/tereree-guavira-viram-sabores-de-cerveja-em-ms/202990/>. Acesso em: 15 abr. 2015. 